\title{
GPPS-CH-2020-0092
}

\section{Application of an Advanced Adaptation Methodology for Gas Turbine Performance Monitoring}

\author{
Pavlos Rompokos \\ National Technical University Athens, \\ Laboratory of Thermal Turbomachines \\ pavlos.rompokos@cranfield.ac.uk \\ Athens, Greece
}

\author{
loannis Roumeliotis ${ }^{1}$ \\ Hellenic Naval Academy \\ i.roumeliotis@cranfield.ac.uk \\ Athens, Greece
}

\author{
Nikolaos Aretakis \\ National Technical University Athens, \\ Laboratory of Thermal Turbomachines \\ naret@central.ntua.gr \\ Athens, Greece \\ Konstantinos Mathioudakis \\ National Technical University Athens, \\ Laboratory of Thermal Turbomachines \\ kmathiou@central.ntua.gr \\ Athens, Greece
}

\begin{abstract}
Adaptive modelling diagnostic methods are valuable tools for gas turbine performance and condition monitoring. Component maps capable of accurate representation of engine operation are not available to the engine operators. In this context, adaptive methods can be used for tuning the component maps for simulating accurately the engine performance throughout the whole operating envelope. In most cases, the map tuning is performed at a single operating point or operating line and although scaled maps can provide accurate results close to the reference points, deviations may significantly increase away from these reference points. For industrial gas turbines, in the past, this was not a major issue, given that most engines operated at or close to baseload. Currently, due to the increased share of renewable power in the generation mix in Europe, there is a shift of industrial gas turbines operating mode from baseload to load following and part load, thus there is a need for accurately simulating engine operation in a broader operating range. This paper presents a component map adaptation methodology integrating several methods applied in the literature in six steps. The novel methodology is applied to on-engine measurements from a heavy-duty gas turbine and the betterment on simulation achieved from each step is quantified. The adapted component maps enable accurate engine condition monitoring as demonstrated by a second test case for an industrial twin shaft engine where operating data spanning over four months are assessed.
\end{abstract}

\section{INTRODUCTION}

One of the major challenges for gas turbine users is to ensure a high level of availability and reliability during the entire operating life of the engine while maintaining efficient operation. For tackling this challenge integration of advanced diagnostic methods can be of great assistance as discussed by Volponi (Volponi, 2014) and demonstrated through applications by (Loboda et al., 2009; Verbist et al., 2013; Roumeliotis et al., 2017). Several diagnostic methods have been proposed for assessing engine health condition (e.g. (Ganguli, 2002; Mathioudakis et al., 2002; Dewallef et al., 2004; Simon et al., 2013)). Among them, model-based methods can directly assess engine overall performance and health condition, providing information that can be used for validating maintenance procedures and for optimizing engine operation. For this purpose, a performance simulation model capable to reproduce the engine operation with acceptable accuracy must be developed. For achieving this suitable component characteristics are needed.

\footnotetext{
${ }^{1}$ Currently Lecturer at Cranfield University
} 
For developing a performance model capable to represent engine operation throughout its operating envelope, component map adaptation through adaptive modelling, as introduced by (Stamatis et al., 1990), has been applied successfully using aircraft on-wing measurements (Verbist et al., 2012; Aretakis et al., 2014) and industrial gas turbine data (Roumeliotis et al., 2017). The application of adaptive modelling includes design point optimisation [e.g. (Lo Gatto et al., 2006)], re-labelling of the isolines (Verbist et al., 2012) and shape adaptation (Tsoutsanis et al., 2014). In the past, most industrial gas turbines operated at baseload mode almost exclusively, thus design point adaptation was an acceptable approximation. Nowadays, due to the increasing share of renewable power in the generation mix in Europe, there is a shift of industrial gas turbine operating mode from baseload to load following and part load, thus the capability of performance models to accurately predict part-load performance is a necessity. In this case, design point optimisation should be complemented by methods that allow performance map isoline shape and distance tuning (re-labelling) for performing suitable multi-point adaptation. Additionally, since electricity generation gas turbines operate at constant rotational speed, variable geometry is used for modulating part-load operation connected to the engine control. Therefore, the change in the map due to variable geometry effect should also be considered, as discussed by (Roumeliotis et al., 2017).

This paper introduces a component characteristic tuning framework that combines the adaptive modelling adaptation methods with on-engine data, for providing reliable engine simulation throughout the whole operating range of interest, for industrial gas turbines. The method is applied to a specific test case, a heavy-duty gas turbine engine operating in combined cycle mode and the benefits that accrue by the different steps in terms of data matching are quantified. The adapted component maps enable improved performance prediction, that can support engine performance and health monitoring. The methodology is applied to a twin-shaft engine configuration as well, demonstrating its ability to produce component maps suitable for performance monitoring of different types of industrial gas turbines.

\section{METHODOLOGY}

\section{Step 1: Map scaling at Design Point}

The first step of the adaptation process is the scaling of the maps to a reference operating point. This process aims to calculate the scaling factors of generic turbomachinery maps associated with the efficiency, corrected mass flow, pressure ratio and corrected rotational speed, relative todesign values. The reference operating point, i.e. the design point, could either be selected from literature or from the available field data. In the latter case, the point selected should reflect as closely as possible standard day conditions $(288.15 \mathrm{~K}, 101325 \mathrm{~Pa}$ and $60 \%$ relative humidity (Volponi, 1999)) and design load operation. For the scaling, the initial point position on every turbomachinery map needs to be provided, using engineering knowledge, for example, surge margin should be considered. The design point position on the maps is defined using the map auxiliary variable BETA for the compressor (Kurzke, 1995) and ZETA for the turbine, as well as the relevant corrected speed line.

\section{Step 2: Field data deviations}

The second step is to define the deviation of model predictions from the measurements using the single point map scaling. Selected operating points are simulated through an off-design calculation and their deviations $(\Delta)$ from the corresponding measured values are recorded, equation (1). Positive or negative values of $\Delta$ correspond to an overestimation or underestimation of the simulated values respectively. An overall view is then provided by calculating the root mean square of the $\Delta$, equation (2).

$$
\Delta=\frac{\text { Simulated }}{\text { Measured }}-1
$$

$$
R M S=\sqrt{\frac{1}{n} \sum_{i=1}^{n} \Delta_{t}^{2}}
$$

\section{Step 3: Map adaptation}

In this step, the engine model is adapted to the measured data, by calculating the map modification factors (Stamatis et al., $\underline{1990)}$ by applying a Newton - Raphson method. These are multiplication parameters for the corrected mass flow and efficiency for every turbomachinery component, as shown in Table 1, and express the shift that needs to be applied to the maps, so that simulated and measured data are as close as possible.

Table 1 Modification factors

\begin{tabular}{|c|c|c|}
\hline Component & Modification Factor & Symbol \\
\hline \multirow{2}{*}{ Compressor } & Flow factor & SCW \\
\cline { 2 - 3 } & Efficiency factor & SCE \\
\hline \multirow{2}{*}{ Turbine } & Flow factor & STW \\
\cline { 2 - 3 } & Efficiency factor & STE \\
\hline
\end{tabular}

\section{Step 4: IGVs factor calculation}

In industrial applications, IGV's are commonly used, especially in single shaft configurations where the mechanical rotational speed remains practically constant and synchronous with the grid frequency for the whole power output range. IGVs effectively change the geometry of the compressor and therefore the performance map. That effect can be captured by a set of factors (one for the corrected flow and one for the efficiency) that shift the compressor maps according to the IGVs angle. At a preliminary stage, these are unknown and can be estimated through the modification factors of step 3. 
SCW and SCE are related to the opening angle of the IGV. Then a best-fit polynomial is applied that provides the IGVs factors throughout operation as a function of the IGV angle measurement.

\section{Step 5: Local map adaptation}

Once the IGV factors have been identified the modification factors are calculated again. If the SCW shows dependency over the corrected rotational speed, local map adaptation is required. This indicates that the map used for the simulation is different from the actual turbomachinery maps. Part of this process is re-labelling (Verbist et al., 2012) and the speed lines are adjusted according to the corresponding SCW mean deviation. The deviation is calculated as shown in equation (3).

$$
\triangle S C W=S C W-1
$$

\section{Step 6: Multi-point design optimisation}

The final step aims to optimise the design point parameters used in step 1, by minimising the root mean square of userselected deviations of adapted-model simulated values from the corresponding measured ones. Any assumed parameter can be chosen, such as component efficiencies, secondary air flows or duct pressure losses. Apart from these parameters, this step primarily aims to optimise the initial design point position on the maps that were arbitrary selected in step 1(i.e. the turbomachinery map auxiliary variables BETA, ZETA and speed lines). In addition, when part load operating points are also considered in this step, the IGVs factors calculated in step 2 need to be included in the optimisation scheme, since different initial position on the maps would dictate different factor values. For the optimisation, the Simplex algorithm is used (Nelder and Mead, 1965) and an optimum solution is searched within a user-predefined value range of each parameter, for ensuring a physical consistent solution. Figure 1 illustrates a schematic representation of the optimisation process. Once all the steps have been completed, local adaptation (step 5) and the optimisation of the initial position on the maps (step 6) can be repeated.

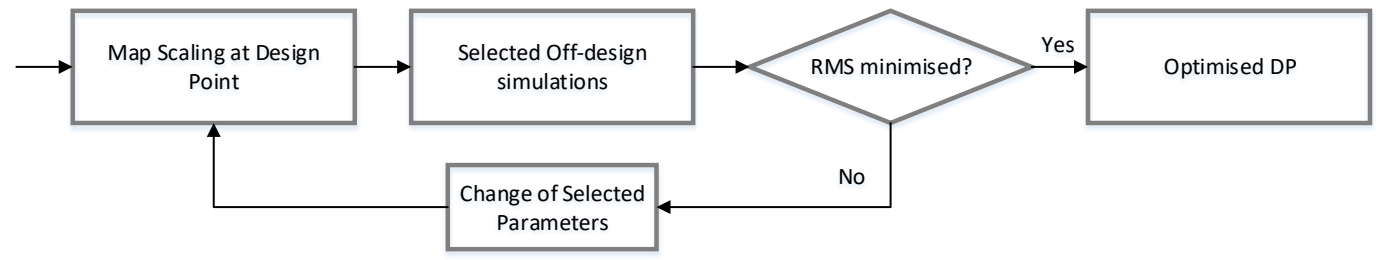

\section{Figure 1 Optimisation steps}

\section{Gas turbine models}

The performance model was built in PROOSIS simulation environment (Emprasarios Agrupados, 2015) by combining gas turbine components from the TURBO library (Alexiou, 2014). These components are connected to create the single shaft configuration model (or schematic in PROOSIS terms) as shown in schematic (a) of Figure 2. For the performance simulations, suitable maps for the compressor and turbine are selected. Duct components are introduced to connect the turbomachinery components and simulate the pressure losses in the inlet and exhaust. At the outlet of the compressor, two bleed-offs are used, one to model the turbine cooling flow and another to model the Inlet Heating Bleed (IHB).

For the calculation of an operating point (off-design simulation) of a single shaft configuration, the mathematical model (or partition in PROOSIS terms) was then defined. The variables selected to be provided as inputs for the calculation were the inlet flow conditions of the compressor (CIT, CIP and WAR), the exhaust pressure, EGP, as well as the power output, PW, and the rotational speed, NP, of the shaft. The choice of these boundary variables forms a nonlinear system of equations, the solution of which requires the initialization of BETA, ZETA, engine inlet air flow rate and the fuel-to-air ratio of the combustor. To solve this system, these four variables are iterated until a corresponding number of residual equations is zeroed within a user-specified tolerance. Hence, for a straight off-design simulation, a 4x4 Jacobian matrix is formed.

For the twin-shaft model, an extra turbine and shaft were added, as well as a duct to connect the two turbines, as shown in schematic (b) of Figure 2. For the off-design calculation, the same boundary conditions are applied as in the single shaft case, with PW referring to the power output of the free turbine and NP its rotational speed. The additional turbomachinery component adds complexity to the solution and another two variables are required to be initialised, forming a $6 \times 6$ Jacobean matrix in this case. ZETA parameter of the power turbine and the rotational speed of the gas generator (NH) are chosen. 


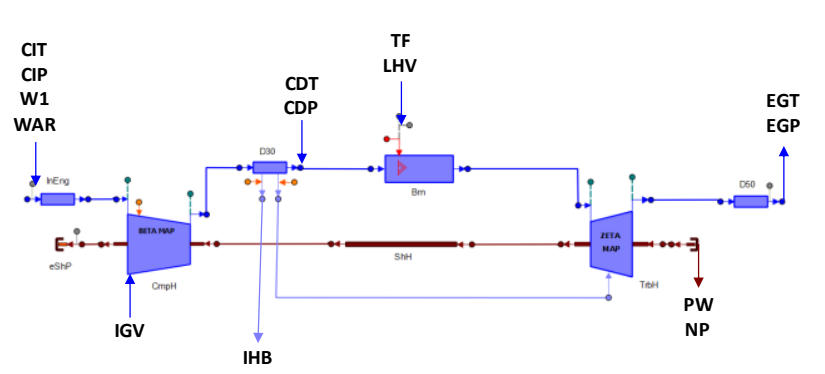

(a)

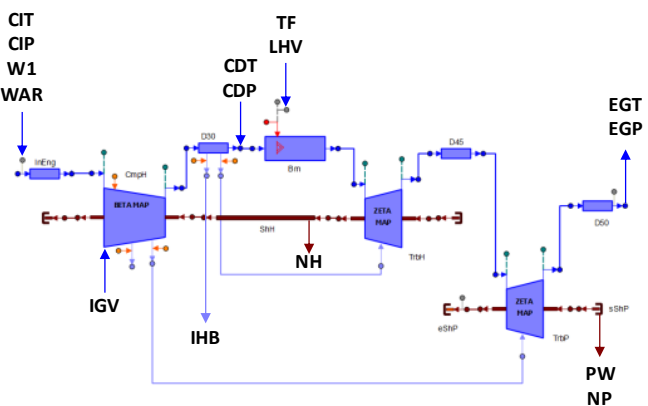

(b)

Figure 2 Schematic models in PROOSIS, (a) single shaft and (b) twin shaft configurations

\section{METHODOLOGY APPLICATION}

\section{Test Case}

The first engine model is adapted on field data of a single shaft heavy-duty gas turbine with a design power output of approximately $250 \mathrm{MW}$ at $50 \mathrm{~Hz}$ with natural gas as a fuel. The data selected cover a wide range of operating conditions, since the temperature at the inlet of the engine in that period varies within a range of $30 \mathrm{~K}$ and the power output is mostly full and half load. The measurements in the installation are recorder frequently but in the context of this application only the ones at steady-state operation (minimum or no change in power output between data sets) are taken into consideration. Additionally, these data were taken from a period of a month right after a compressor wash, so that the model would reflect the "healthy" operation of the gas turbine. Adapting the model to all these data is of high importance as it would increase its predicting accuracy.

A few key measurements are power output (PW), compressor exit temperature (CDT) and pressure (CDP) and exhaust gas temperature (EGT). In Figure 3, these terms are presented corrected for ambient temperature and pressure (Volponi, 1999) and relative to the reference value of the design point, which was selected from the available dataset. The full and half load operation is evident in all the diagrams of Figure 3, as the measurements are gathered around two mean lines.Additional measurements are the shaft rotational speed, compressor inlet temperature and pressure, inlet mass flow (W1), IGVs angle, the temperature and lower heating value of the fuel as quoted by the natural gas supplier.

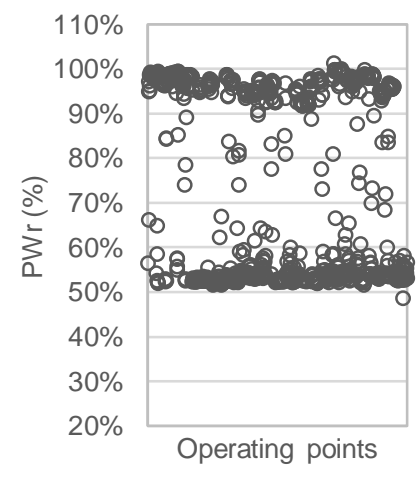

(a)

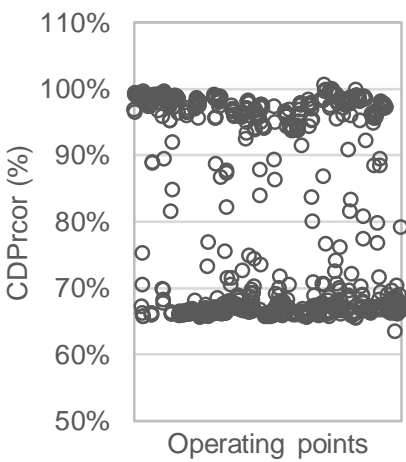

(b)

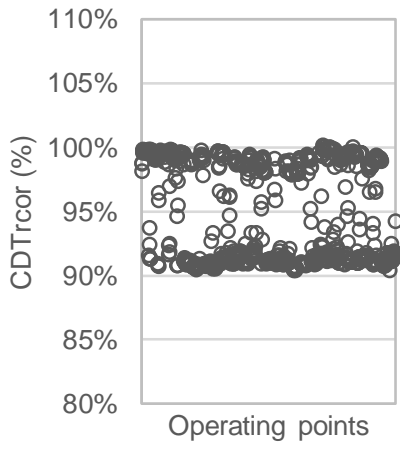

(c)

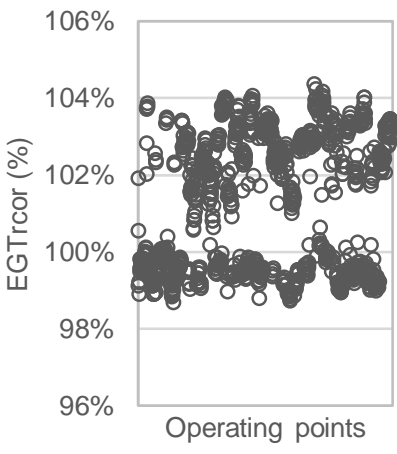

(d)

Figure 3 (a) power output, (b) CDP, (c) CDT and (d) EGT corrected for ambient conditions and related to their reference values.

\section{Model adaptation}

\section{Step 1 Map scaling at design point}

In the first step, the turbomachinery map scalars, as described in the previous section, are calculated. In a modified version of the mathematical model established for the off-design calculation, the scalars are treated as unknowns and are sized according to the measured values of the CDT, CDP W1 and EGT of the design point chosen and an assumed initial position of the design point on the turbomachinery maps. 


\section{Step 2 Field data deviations}

Once the maps have been scaled to the design point the remaining operating points were simulated. For the off-design calculations, the pressure losses of the ducts across the engine were set to vary as a function of mass flow rate and the burner efficiency was set as a function of burner loading (Walsh and Fletcher, 2004). Fuel lower heating value (LHV) and temperature (TF) were set as inputs by the user, for their values differ according to the supply. IGV reference to maximum opening was also an input to the model. However since the IGV correction factors are yet unknown, it did not affect the calculation. The engine is also equipped with inlet air heating that operates at part load to ensure combustor stability. Compressed air is extracted through the IHB at the exit of the compressor and is mixed with the inlet air. The IHB is modelled as a bleed-off at the exit of the compressor and its value imposed by a schedule related to the IGV angle. When IHB is applied the engine inlet temperature increases relative to the ambient conditions, and this information (ambient air heating) is provided by the compressor inlet air temperature measurement. The power output of the shaft is calculated as the indicated power of the generator corrected for the generator efficiency.

The deviations of the simulated data from the corresponding measurements have been calculated and their RMS are presented in Figure 4 in terms of full load, graph (a), and part load, graph (b). The first thing noted is that for full load, i.e. in the proximity of the design point, the simulated operating points present relatively small deviations across all the available measurements. However, this is not the case for the part-load since the deviations there are larger, e.g. W1 with an RMS of approximately $35 \%$. Considering that the rotational speed of the shaft is approximately constant across the whole load range, all the simulated operating points are located in the area of the same corrected speed-line of the compressor map. Since no corrections for the IGV opening are yet applied, operating in one compressor speed line would dictate a small range of corrected mass flow close to design conditions for all load range. Consequently, that would lead to overprediction of the mass flow required as well as the CDT and CDP.

Full load

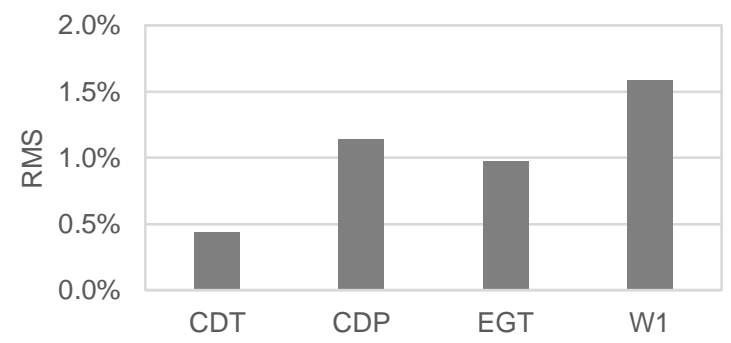

(a)

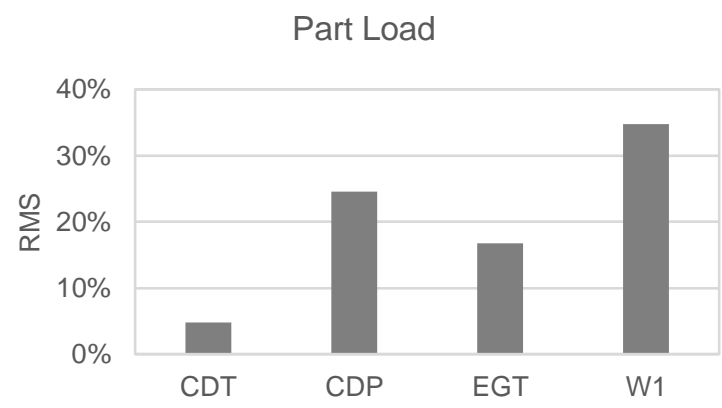

(b)

Figure 4 RMS of field data deviations for full load (a) and part load (b)

\section{Step 3 Adaptation factor calculation}

Better insight into the maps sized at design point is then obtained by calculating the relevant modification factors. For this calculation, another modified version of the off-design calculation is used where the modification factors are set as unknowns and an equivalent number of inputs are provided. In this case CDP, CDT, W1 and EGT are considered for every operating point. It is worth noting that in this case W1 was measured, however, if it is not available, the fuel flow could be used as an alternative. The deviations of the factors as calculated by equations (3) are presented in Figure 5. Their deviations are concentrated around two mean lines, one close to $0 \%$ reflecting the full load and another one, varying depending on the component, which reflects the part-load operation. The need to correct the maps according to the IGV opening is evident, as indicated by the deviations in $\triangle \mathrm{SCW}$.
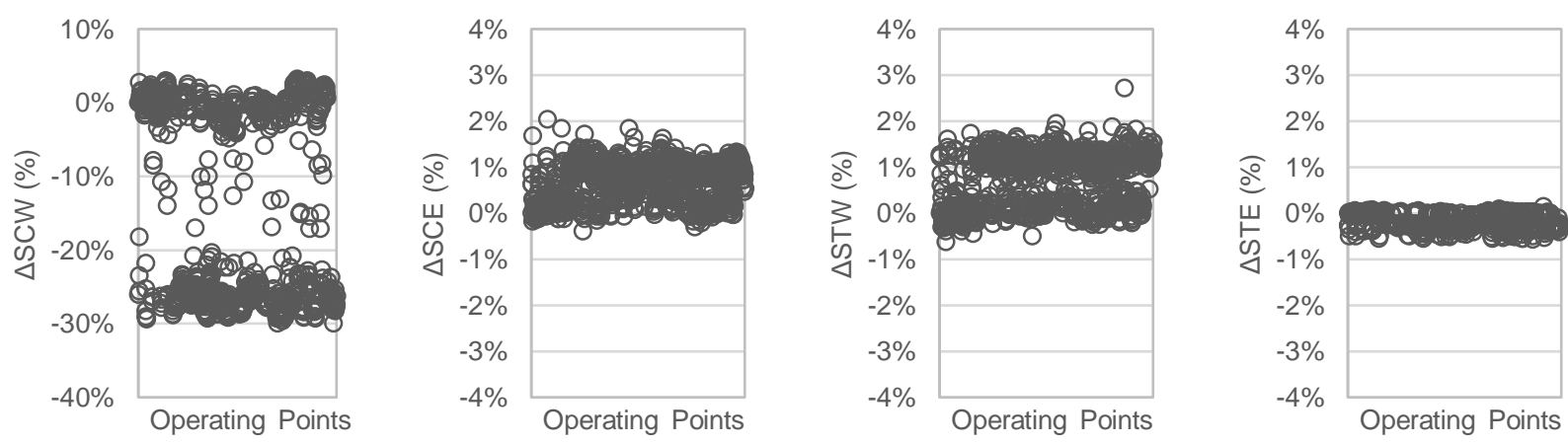

Figure 5 Modification factors as calculated after the map scaling at design point 


\section{Step 4: IGVs factor calculation}

When plotting the calculated SCW relative to the IGV angle, as shown in graph (a) of Figure 6, a clear correlation appears. The simulated data are approached by a second-degree polynomial which intercepts the value 1.0 when the IGVs are fully open. Similar behaviour for the SCE factors was not evident and therefore no correction was applied. The adaptation factors are once more calculated for the IGV factors obtained and the RMS of SCW deviations are presented in graph (b) of Figure 6 comparative to the previous calculation. It is noted that only SCW changed. The gap between full and part load is now minimised and the modification factor deviations present an RMS of $1.5 \%$.

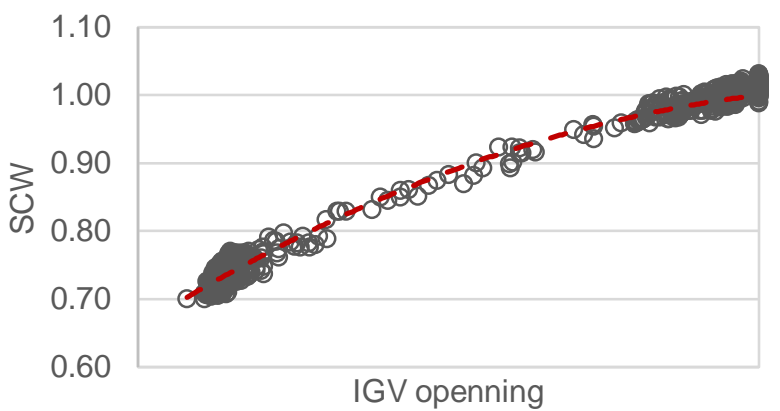

(a)

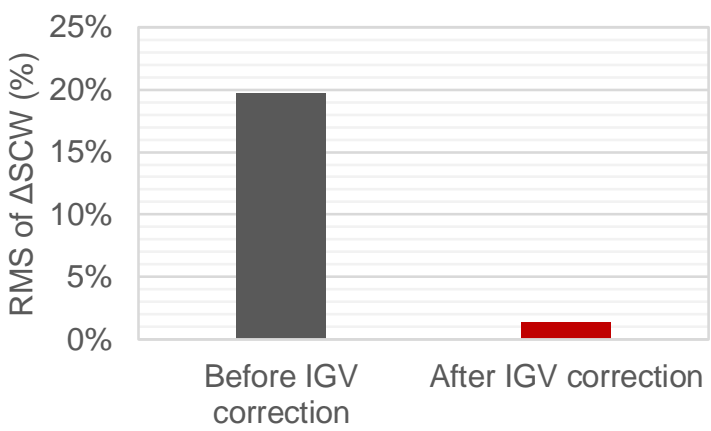

(b)

Figure 6 Compressor flow modification factor to IGV angle opening

\section{Step 5: Local map adaptation}

Next step is to examine if relabelling of the speed lines of the compressor map is required. In graph (a) of Figure 7, the dependency of the SCW deviations to the unscaled speed lines of the map is shown and the correction is applied only to the range of speed-lines that there are data. In graph (b) of Figure 7, the modification factors are recalculated and the and the RMS of their deviations is slightly improved. This step demonstrates how the compressor map used is not entirely fit for the particular applications and modification is required. This is also the reason why this step precedes the optimisation of the initial position of the design point in the maps, as it was considered that searching for it in an unsuitable map would not lead to accurate results.

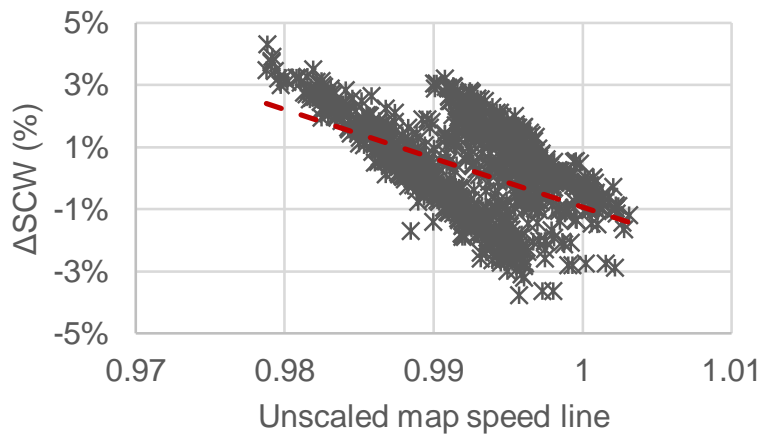

(a)

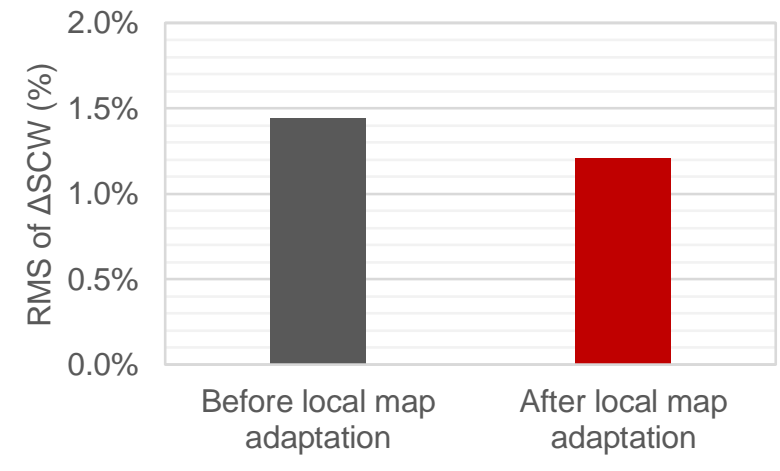

(b)

Figure 7 Left diagram: SCW against map speed-line. Right diagram: SCW before and after the map adaptation

\section{Step 6: Optimisation}

In this step, the position of the design point in the turbomachinery maps was optimised. The deviations of CDP, CDT, W1 and EGT for all the operating points available were selected to be minimised, by changing the BETA, ZETA and speed-lines of the design point, as well as the IGV correction factors calculated in step 4. The latter is necessary as by changing the design point on the maps would dictate different IGV correction factors every time. The results of the optimisation are again shown in terms of deviations of the modification factors in Figure 8. Values previously scattered around two mean lines are now gathered around $0 \%$ in all cases. 

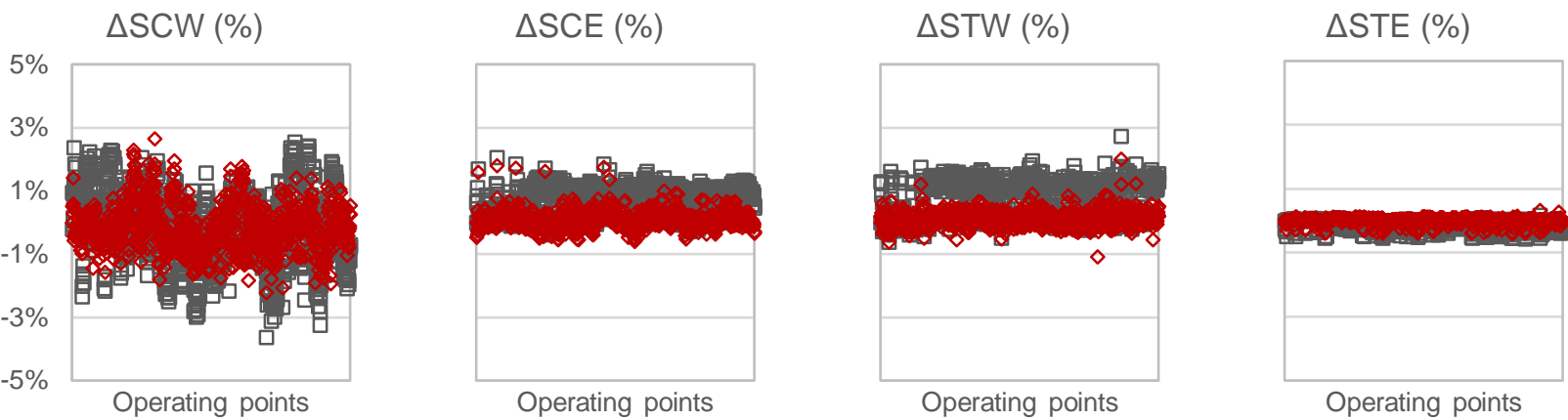

口Before optimisation

$\diamond$ After Optimisation

Figure 8 Modification factors before and after optimisation

\section{Additional iteration: 2nd Local map adaptation}

The whole process is checked from the beginning for further improvement. IGV correction factors are already optimised in the previous step, making it unnecessary to recalculate. However, when checking for local map adaptation another correction could be applied, as all the deviations of SCW are gathered around a single line, as shown in graph (a) of Figure 9. The map is modified accordingly. The results are presented comparatively to the previous step in graph (b) of Figure 9. The RMS of SCW deviations was minimised to $0.5 \%$. The optimisation step is yet again examined, however, it does not further improve the model. Finally, the simulated operating points calculated from the adapted model and their deviations from the measured values are presented in Figure 10.

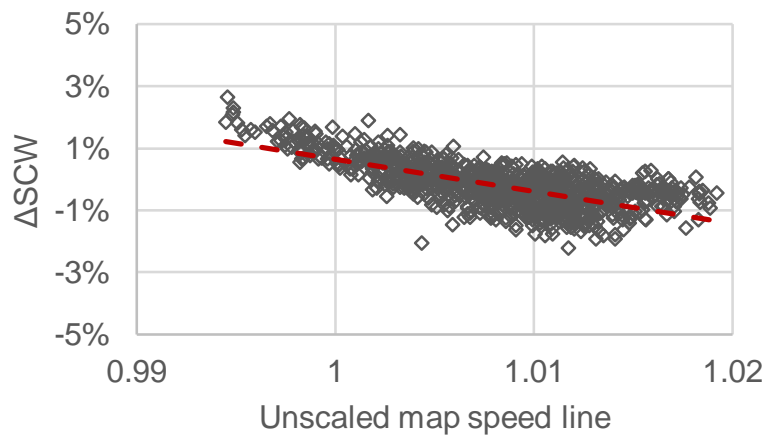

(a)

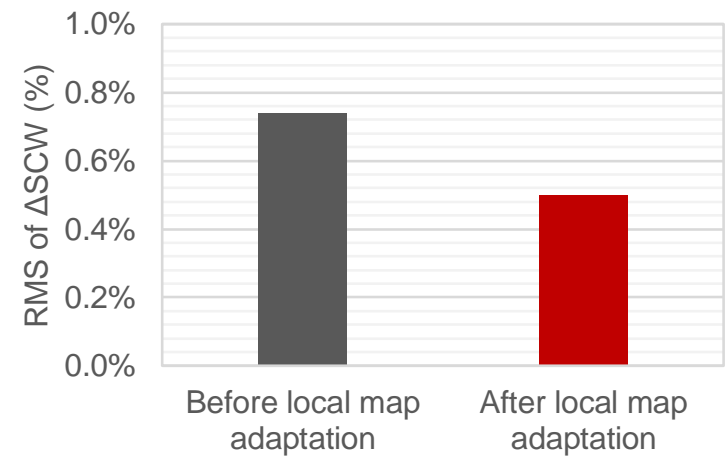

(b)

Figure 9 Left diagram: SCW against map speed-line. Right diagram SCW before and after the second map adaptation

Full load

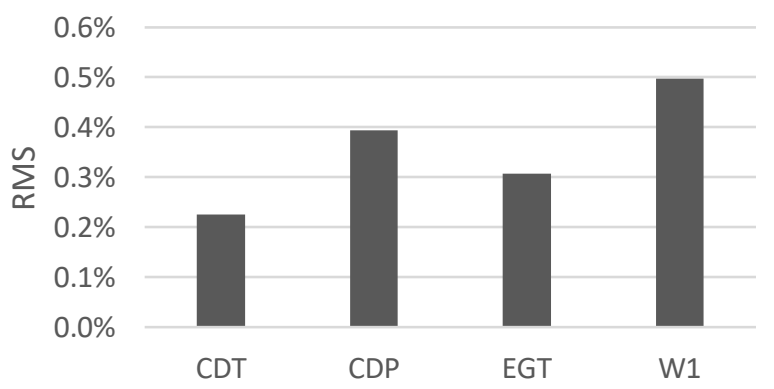

(a)
Part Load

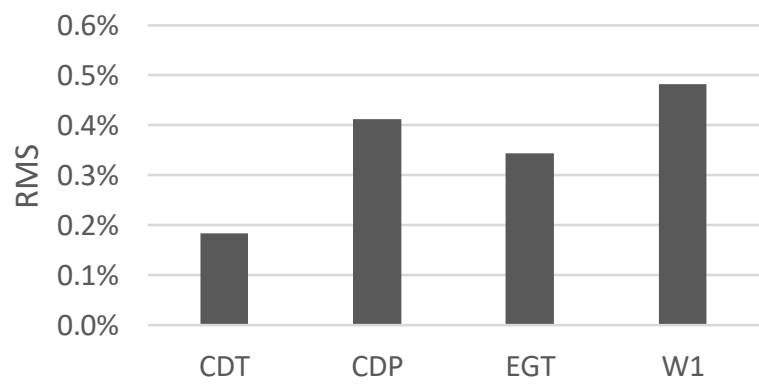

(b)

Figure 10 RMS of field data deviations of the final adapted model for full load (a) and part load (b) 


\section{APPLICATION FOR PERFORMANCE MONITORING}

\section{Engine and data description}

Application of the adaptation procedure was also performed on a twin shaft industrial gas turbine. Its design power output is approximately $20 \mathrm{MW}$ at $50 \mathrm{~Hz}$ and uses liquid fuel. The field data available cover four-month period of operation and dictate that the engine is operated constantly at approximately $80-85 \%$ of the design load. The external temperature for that period varies within a range of approximately $30 \mathrm{~K}$. The available measurements are compressor inlet and outlet temperature and pressure (CIT, CIP, CDT, CDP respectively), the inlet mass flow (W1), the exhaust gas temperature (EGT), the rotational speed of the gas generator $(\mathrm{NH})$ and the power turbine (NP), as well as the indication of the power output of the generator (PW). In Figure 11, PW, W1 and EGT measurements of the operating points are presented corrected for ambient pressure and temperature and normalised according to their reference values of the design point provided by the OEM. The corrected values highlight a period where the parameters change inconsistently. For example, during the circled period the corrected power production remains almost constant but the corrected EGT increases significantly indicating a possible degradation of the engine. To assess the engine condition the method discussed was applied for deriving the components maps and then used for diagnosis.

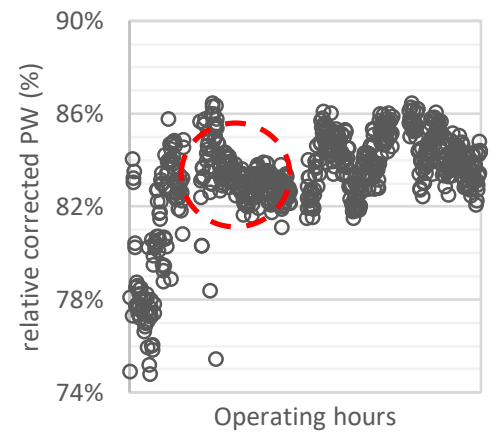

(a)

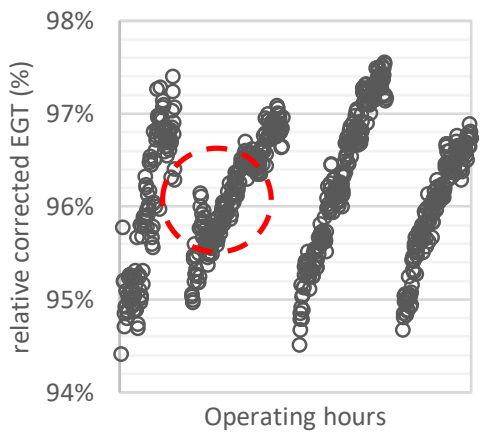

(b)

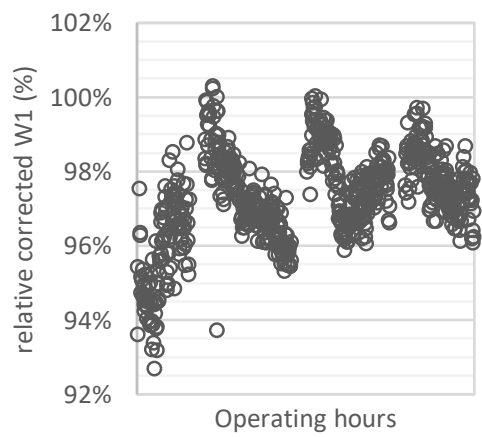

(c)

Figure 11 (a) corrected load relative to the reference value. (b) corrected EGT relative to the reference value. (c) corrected compressor mass flow rate relative to reference value

\section{Model adaptation and performance monitoring}

The turbomachinery maps were originally scaled at the reference design point provided by the OEM through an extended version of the off-design calculation, similarly to the single-shaft case. Since not all the required inputs were available some parameters were assumed.

In the twin shaft case, the power turbine adds an extra turbomachinery map and therefore two additional modification factors could be considered in the adaptation process, one for mass flow (SPTW) and one for the efficiency (SPTE) of the power turbine. For the calculation of the modification factors, as previously, an extended version of the off-design simulation was created. However, in this case, the available measurements (that are not used in the off-design calculation) are five, namely CDT, CDP, W1, EGT and NH. Consequently, it is only possible to calculate five out of six factors. In this case, the SPTE was not calculated.

The final adapted model was obtained by applying the adaptation framework presented. Multi-point optimisation was performed to correct the initial map scaling by minimizing the differences between calculated and measured values of W1, CDT, CDP, EGT and NH. Two optimisation schemes were performed, one taking into account only the operating points referring to healthy operation, after compressor washing, and one using all available points. The results were similar in both cases. Applying the data after a washing provides marginally better results reducing the variation and the relevant maps were applied for the measurement analysis.

In Figure 12 the deviations of the modification factors of the adapted model are shown before and after all corrections. By examining the $\triangle \mathrm{SCW}$ and $\triangle \mathrm{SCE}$, the degradation of the compressor over time can be observed, as well as the several washings performed to restore it to clean conditions. The turbines performance does not change over the examined period, indicating that there is no sign of turbine degradation over time. 

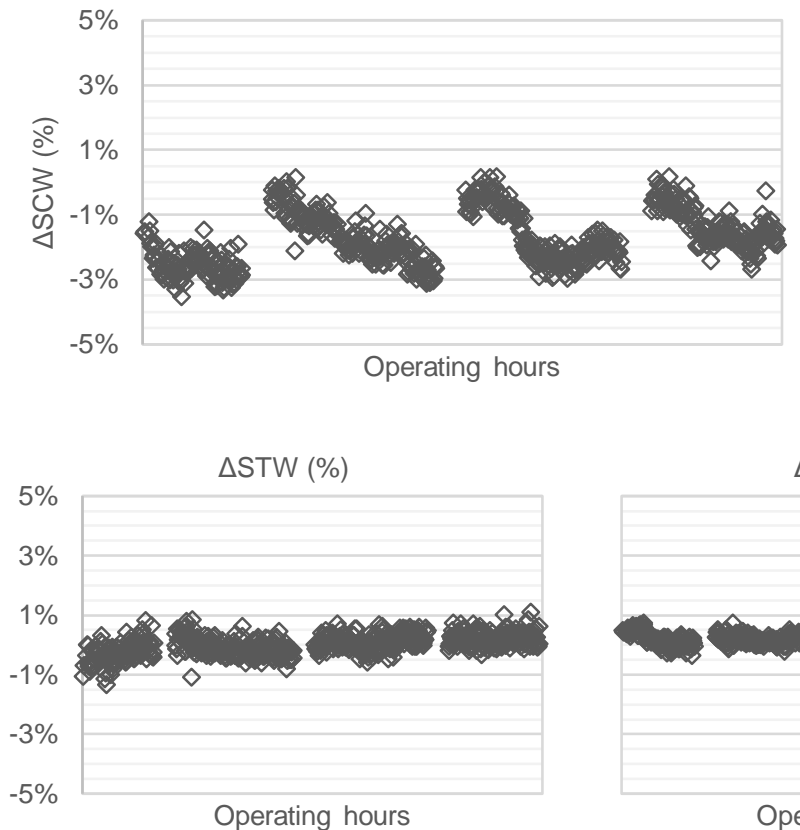

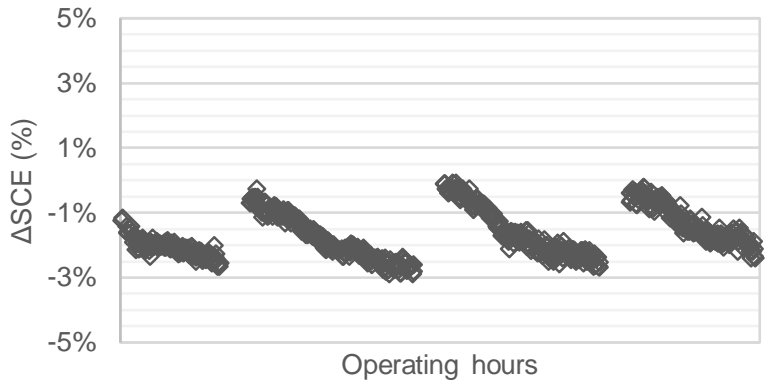

$\triangle \operatorname{STE}(\%)$
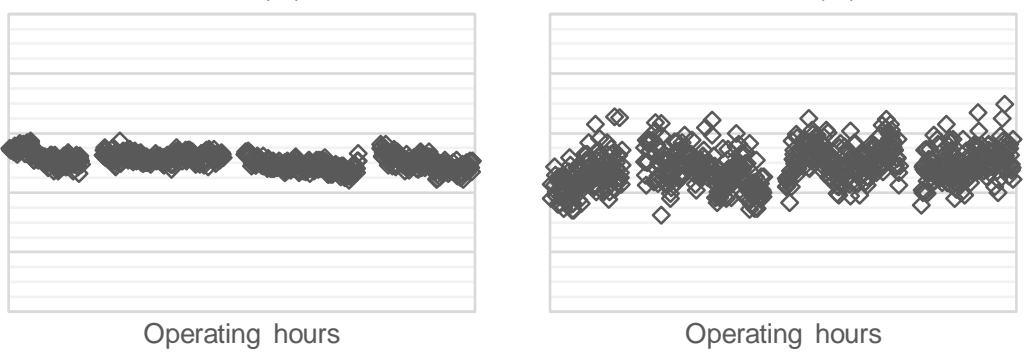

Operating hours

Figure 12 Modification factors of the adapted model

\section{CONCLUSIONS}

An adaptation framework integrating different component map tuning methods has been developed for delivering maps suitable for reproducing industrial gas turbine operation over an extended operating range, suitable for monitoring load-following units. The different steps and methods of the semi-automated procedure were described and the benefits accrued after each step on the simulation accuracy has been quantified for the test case of a heavy-duty gas turbine operating at combined cycle. The method then was applied to a twin shaft industrial gas turbine demonstrating its ability to produce component maps suitable for performance monitoring for a different type of industrial gas turbines.

Map scaling at design point provided adequate accuracy only for operating condition s close to design point, whereas part-load operation deviated significantly from the measurements. IGV correction was then applied to improve the partload performance of the model, leading to accuracy in the range of $1.5 \%$ for the whole operating range. Via re-labelling the ambient temperature effect on the isolines was captured reducing the deviation. Following design point, optimisation, the engine model presented an overall deviation of less than $1 \%$, while a second re-labelling further reduced that to less than $0.5 \%$ for all modification factors, for the whole operating range and different ambient conditions. The resulting adapted model is suitable for accurate engine performance monitoring.

\section{NOMENCLATURE}

Units Description

$\begin{array}{lcl}\text { BETA } & - & \text { Compressor map auxiliary variable } \\ \text { CDP } & \mathrm{Pa} & \text { Compressor Discharge Pressure } \\ \text { CDT } & \mathrm{K} & \text { Compressor Discharge Temperature } \\ \text { CIP } & \mathrm{Pa} & \text { Compressor Inlet Pressure } \\ \text { CIT } & \mathrm{K} & \text { Compressor Inlet Temperature } \\ \text { EGP } & \mathrm{Pa} & \text { Exhaust Gas Pressure } \\ \text { IGVs } & - & \text { Inlet Guide Vanes } \\ \text { IHB } & - & \text { Inlet Heating Bleed } \\ \text { LHV } & \mathrm{J} / \mathrm{kg} & \text { Lower Heating Value } \\ \text { NH } & \mathrm{rpm} & \text { Rotational speed of the gas generator shaft } \\ \text { NP } & \mathrm{rpm} & \text { Rotational speed of the shaft connected to the generator } \\ \text { OEM } & - & \text { Original Equipment Manufacturer } \\ \text { PW } & \mathrm{W} & \text { Power output }\end{array}$




$\begin{array}{lcl}\text { RMS } & - & \text { Root Mean Square } \\ \text { TF } & \mathrm{K} & \text { Injected Fuel Temperature } \\ \mathrm{W} 1 & \mathrm{~kg} / \mathrm{s} & \text { Air mass flow rate at the inlet } \\ \text { WAR } & \mathrm{kg}_{\text {water }} / \mathrm{kg}_{\text {air }} & \text { Water to air ratio } \\ \text { ZETA } & - & \text { Turbine map auxiliary variable }\end{array}$

\section{ACKNOWLEDGEMENTS}

The authors would like to thank P. Kalogridis and Dr A. Alexiou for their contribution towards the development of the models.

\section{REFERENCES}

Alexiou, A. (2014) Introduction to Gas Turbine Modelling with PROOSIS. Second. Athens: Laboratory of Thermal Turbomachines, NTUA.

Aretakis, N., Roumeliotis, I., Alexiou, A., Romesis, C. and Mathioudakis, K. (2014) 'Turbofan Engine Health Assessment From Flight Data', Journal of Engineering for Gas Turbines and Power, 137(4), p. 041203. doi: 10.1115/1.4028566.

Dewallef, P., Romessis, C., Léonard, O. and Mathioudakis, K. (2004) 'Combining Classification Techniques With Kalman Filters for Aircraft Engine Diagnostics', Journal of Engineering for Gas Turbines and Power, 128(2), pp. 281-287. doi: 10.1115/1.2056507.

Emprasarios Agrupados (2015) Proosis 3.6 User Manual. Empresarios Agrupados.

Ganguli, R. (2002) 'Fuzzy Logic Intelligent System for Gas Turbine Module and System Fault Isolation', Journal of Propulsion and Power. American Institute of Aeronautics and Astronautics, 18(2), pp. 440-447. doi: 10.2514/2.5953.

Lo Gatto, E., Li, Y. G. and Pilidis, P. (2006) ‘Gas Turbine Off-Design Performance Adaptation Using a Genetic Algorithm', pp. 551-560. doi: 10.1115/GT2006-90299.

Kurzke, J. (1995) 'Advanced User-Friendly Gas Turbine Performance Calculations on a Personal Computer', in International Gas Turbine and Aeroegine Congress and Exposition. Huston, Texas. doi: 10.1115/95-GT-147.

Loboda, I., Yepifanov, S. and Feldshteyn, Y. (2009) 'Diagnostic Analysis of Maintenance Data of a Gas Turbine for Driving an Electric Generator', in Proceedings of ASME Turbo Expo 2009: Power for Land, Sea and Air. Orlando, Florida, USA, pp. 745-756. doi: 10.1115/GT2009-60176.

Mathioudakis, K., Kamboukos, P. and Stamatis, A. (2002) ‘Turbofan Performance Deterioration Tracking Using Nonlinear Models and Optimization Techniques', Journal of Turbomachinery, 124(4), pp. 580-587. doi: 10.1115/1.1512678.

Nelder, J. A. and Mead, R. (1965) 'A Simplex Method for Function Minimization', The Computer Journal, 7(4), pp. 308313. doi: $10.1093 /$ comjnl/7.4.308.

Roumeliotis, I., Aretakis, N. and Alexiou, A. (2017) 'Industrial Gas Turbine Health and Performance Assessment With Field Data', Journal of Engineering for Gas Turbines and Power, 139(5). doi: 10.1115/1.4034986.

Simon, D. L., Borguet, S., Léonard, O. and Zhang, X. (Frank) (2013) 'Aircraft Engine Gas Path Diagnostic Methods: Public Benchmarking Results', Journal of Engineering for Gas Turbines and Power, 136(4). doi: 10.1115/1.4025482.

Stamatis, A., Mathioudakis, K. and Papailiou, K. D. (1990) 'Adaptive Simulation of Gas Turbine Performance', Journal of Engineering for Gas Turbines and Power, 112(2), pp. 168-175. doi: 10.1115/1.2906157.

Tsoutsanis, E., Meskin, N., Benammar, M. and Khorasani, K. (2014) 'A component map tuning method for performance prediction and diagnostics of gas turbine compressors', Applied Energy, 135, pp. 572-585. doi: https://doi.org/10.1016/j.apenergy.2014.08.115.

Verbist, M. L., Visser, W. P. J. and van Buijtenen, J. P. (2013) 'Experience With Gas Path Analysis for On-Wing Turbofan Condition Monitoring', Journal of Engineering for Gas Turbines and Power, 136(1). doi: 10.1115/1.4025347.

Verbist, M. L., Visser, W. P. J., Pecnik, R. and van Buijtenen, J. P. (2012) 'Component Map Tuning Procedure Using Adaptive Modeling', in Proceedings of ASME Turbo Expo 2012. Copenhagen, Denmark, pp. 371-379. doi: 10.1115/GT2012-69688.

Volponi, A. J. (1999) 'Gas Turbine Parameter Corrections', Journal of Engineering for Gas Turbines and Power, 121(4), pp. 613-621. doi: 10.1115/1.2818516.

Volponi, A. J. (2014) 'Gas Turbine Engine Health Management: Past, Present, and Future Trends', Journal of Engineering for Gas Turbines and Power, 136(5). doi: 10.1115/1.4026126.

Walsh, P. and Fletcher, P. (2004) Gas Turbine Performance. Second, John Wiley \& Sons, Inc. Second. Blackwell Science Ltd. 